\title{
Effective biodegradation of 2,4,6-trinitrotoluene using a novel bacterial strain isolated from TNT-contaminated soil
}

\author{
Burcu Gumuscu $^{\text {a,d }}$, Turgay Tekinay ${ }^{\text {a,b,c,* }}$ \\ a Bilkent University, UNAM - Institute of Materials Science and Nanotechnology, 06800 Ankara, Turkey \\ ${ }^{\mathrm{b}}$ Gazi University, Life Sciences Application and Research Center, 06830 Ankara, Turkey \\ ${ }^{\mathrm{C}}$ Gazi University, Polath Science and Literature Faculty, 06900 Ankara, Turkey \\ ${ }^{\mathrm{d}}$ University of Twente, MESA+ Institute for Nanotechnology, 75100 AE Enschede, The Netherlands
}

\section{A R T I C L E I N F O}

\section{Article history:}

Received 24 May 2013

Received in revised form

10 June 2013

Accepted 12 June 2013

Available online 11 July 2013

\section{Keywords:}

2,4,6-Trinitrotoluene (TNT)

Dinitrotoluenes (DNTs)

Nitroaromatic compounds

Biodegradation

Achromobacter spanius STE 11

\begin{abstract}
A B S T R A C T
In this environmental-sample based study, rapid microbial-mediated degradation of 2,4,6-trinitrotoluene (TNT) contaminated soils is demonstrated by a novel strain, Achromobacter spanius STE 11. Complete removal of $100 \mathrm{mg} \mathrm{L}^{-1}$ TNT is achieved within only $20 \mathrm{~h}$ under aerobic conditions by the isolate. In this bio-conversion process, TNT is transformed to 2,4-dinitrotoluene $\left(7 \mathrm{mg} \mathrm{L}^{-1}\right), 2,6$-dinitrotoluene $\left(3 \mathrm{mg} \mathrm{L}^{-1}\right)$, 4-aminodinitrotoluene $\left(49 \mathrm{mg} \mathrm{L}^{-1}\right)$ and 2-aminodinitrotoluene $\left(16 \mathrm{mg} \mathrm{L}^{-1}\right)$ as the key metabolites. A. spanius STE 11 has the ability to denitrate TNT in aerobic conditions as suggested by the dinitrotoluene and $\mathrm{NO}_{3}$ productions during the growth period. Elemental analysis results indicate that $24.77 \mathrm{mg} \mathrm{L}^{-1}$ nitrogen from TNT was accumulated in the cell biomass, showing that STE 11 can use TNT as its sole nitrogen source. TNT degradation was observed between pH 4.0-8.0 and $4-43^{\circ} \mathrm{C}$; however, the most efficient degradation was at $\mathrm{pH} 6.0-7.0$ and $30^{\circ} \mathrm{C}$.
\end{abstract}

(c) 2013 Elsevier Ltd. All rights reserved.

\section{Introduction}

Starting in the 19th century, 2,4,6-trinitrotoluene (TNT) was widely produced and used as an explosive material for both military and mining purposes. Extensive TNT usage resulted in serious contamination problems in many water sources and soil (EPA, 1989; Spain et al., 2000). Therefore, the United States Environmental Protection Agency (US EPA) considers TNT as a major contaminant and lists it as a priority mutagenic and carcinogenic material (EPA, 1989). Occupational or incidental exposures to TNT have several negative effects on human health, including skin irritation, disturbance of liver function, anemia, and/or spermatozoa damages (Rieger and Knackmuss, 1995; Letzel et al., 2003). Therefore, it is essential to reduce the negative long-term impacts of TNT on living organisms and to minimize the detrimental impacts of this contaminant on the environment (Spain et al., 2000).

To date, many studies reported the remediation of TNT in contaminated lands, including ex situ and in situ techniques. Previously studied ex situ techniques are primarily incineration, wet air oxidation (Hao et al., 1993), and photocatalytic degradation (Dillert

\footnotetext{
* Corresponding author. Gazi University Golbasi Campus, 06830, Golbasi, Ankara, Turkey. Tel: +90 312484 6270; fax: +90 3124846271 .

E-mail address: ttekinay@gazi.edu.tr (T. Tekinay).
}

et al., 1995). Incineration, namely the removal of nitroaromatic compounds by combustion, is one of the long established ex situ methods for reducing TNT contamination. Other ex situ methods include wet air oxidation - in which soluble complex organic compounds are oxidized by the use of air in an aqueous solution under high temperature and pressure conditions (Hao et al., 1993). Photocatalytic degradation is an alternative ex situ method based on exposing photons to excite electrons from the valence to the conduction band in order to generate free radicals that then oxidize nitroaromatic molecules (Dillert et al., 1995). However, high implementation costs and the formation of toxic end products limit the implementation of these techniques. Thus, current studies are mainly focused on bioremediation by in situ methods. Fungi (Gao et al., 2010), plants (Rylott and Bruce, 2009), anaerobic bacteria (Drzyzga et al., 1998; Kalafut et al., 1998), and aerobic bacteria (Drzyzga et al., 1998) have been extensively studied to identify efficient techniques for the in situ remediation of TNT. Fungi can tolerate high concentrations of nitroaromatic explosives; however, they cannot survive in harsh environmental conditions such as high temperatures and pH (Spain et al., 2000). Genetically modified plants have been used for the bioremediation of nitroaromatics; though this approach has proved unfavorable since genetically modified organisms are subject to ethical and environmental discussions (Snellinx et al., 2002; Gandia-Herrero et al., 2008; Rylott 
and Bruce, 2009; Macek et al., 2012). While it is known that anaerobic bacteria are capable of transforming TNT into the environmentally benign degradation product 2,4,6-triaminotoluene (Smets et al., 2007), strict anoxic conditions are essential for this process. Bioremediation by aerobic bacteria is a promising alternative to current techniques, leading to high TNT reduction rates, environmentally friendly degradation products, low operating costs and the widespread presence of such microorganisms in the environment (Drzyzga et al., 1998; Spain et al., 2000).

Extensive research has been done to elucidate the pathways of TNT transformation under aerobic conditions (Vorbeck et al., 1998; Spain et al., 2000; Cohen et al., 2007). The most effective route of TNT reduction involves the conversion of nitro groups into nitroso, hydroxylamino and amino groups (Sitzmann, 1974; Lewis et al., 2004). Several byproducts and metabolites such as 2,4-dinitrotoluene (2,4-DNT); 2,6-dinitrotoluene (2,6-DNT); 2-aminodinitrotoluene (2-ADNT); and 4-aminodinitrotoluene (4-ADNT) are formed during this process (Schmidt et al., 2006). Recent studies demonstrated that complete TNT degradation by aerobic bacteria resulted in accumulation of ADNTs as key metabolites (Solyanikova et al., 2012).

In this work, Achromobacter spanius STE 11 was isolated from TNT-contaminated soils and the bacterial isolate was shown to degrade TNT only in $20 \mathrm{~h}$ with a high degradation success. In this study, TNT metabolites were identified; optimum temperature and $\mathrm{pH}$ conditions together with the effect of an additional nitrogen source on degradation capacity were investigated. Data from HPLC, FT-IR spectroscopy, elemental analysis and colorimetric tests provided more insights into whether TNT could be removed by the strain STE 11.

\section{Materials and methods}

\subsection{Culture conditions and chemicals}

The TNT degradation capabilities of the isolate were assessed by M8 medium (Sambrook and Russell, 2001) which contained $60 \mathrm{~g} \mathrm{~L}^{-1} \mathrm{Na} 2 \mathrm{HPO} 4,30 \mathrm{~g} \mathrm{~L}^{-1} \mathrm{KH} 2 \mathrm{PO} 4,5 \mathrm{~g} \mathrm{~L}^{-1} \mathrm{NaCl}, 10 \mathrm{~mL}$ of $5 \%$ glucose, and $100 \mathrm{mg} \mathrm{L}^{-1}$ TNT. The effect of an additional nitrogen source on TNT degradation was investigated by using M9 medium (Kubota et al., 2008). M8 and M9 media were autoclaved at $121^{\circ} \mathrm{C}$ for 15 min after addition of all components. In all experiments, STE 11 strain was incubated overnight in the dark at $30^{\circ} \mathrm{C}$. All aqueous cultures were agitated on a rotary shaker operating at $125 \mathrm{rpm}$. Bacterial growth was monitored by turbidity measurements at $600 \mathrm{~nm}$, using a SpectraMax Microplate Reader M5/M5 ${ }^{\mathrm{e}}$ (Molecular Devices, USA).

The analytical grade standards of TNT, 2,6-DNT, 4-ADNT, and 2-ADNT $(1000 \mu \mathrm{g} / \mathrm{mL}$ in acetonitrile, purity $>99.0 \%)$ were purchased from SupelCo (USA). An intermediate stock solution of 2,4DNT was prepared by dissolving powder 2,4-DNT (SupelCo, USA) in acetonitrile at the concentration of $1000 \mu \mathrm{g} \mathrm{mL}^{-1}$. The calibration curve was generated between 0.05 and $1 \mathrm{mg} \mathrm{L}^{-1}$ of spiked samples. The curve was then used to calculate the concentration of TNT and its derivatives in culture media. Double distilled water (Millipore, USA) and HPLC-grade acetonitrile (Sigma-Aldrich, USA) were used in the HPLC measurements.

\subsection{Soil}

Soil samples were collected from a TNT manufacturing and mine explosion site in Elmadag, Turkey ( $+39^{\circ} 49^{\prime} 56.58^{\prime \prime},+33^{\circ} 31^{\prime} 5.57^{\prime \prime}$ ). The sampling sites have been contaminated over 50 years by munitions use. Samples were collected from visible soil discoloration sections, bulky regions, pink waters, and bottom sediments of pink water regions. Soil was removed using spatulas to a depth of 5$10 \mathrm{~cm}$ and enclosed in separate sterile $50 \mathrm{~mL}$ polypropylene conical tubes. TNT concentrations of the samples were found to be between 20 and $245 \mathrm{mg} / \mathrm{kg}$. The moisture level was found to be $20-35 \%$ for soil samples and $60-78 \%$ for mud samples. For moisture measurements, $1-3 \mathrm{~g}$ of sample was oven-dried $\left(105^{\circ} \mathrm{C}\right)$ for $24 \mathrm{~h}$. Moisture content wet basis was calculated with the equation MC $\%=\left(W_{\mathrm{i}}-W_{\mathrm{f}}\right) / W_{\mathrm{i}} \times 100$; where MC\% is moisture content, $W_{\mathrm{i}}$ is the initial weight, and $W_{\mathrm{f}}$ is the final weight.

\subsection{Isolation and identification}

The collected samples were immediately inoculated in M8 media $(0.1 \%, w / v$ or $v / v)$. On the fourth day, the inocula were transferred to secondary cultures. The resulting bacterial enrichments were transferred to a M8 medium $(0.1 \%, v / v)$ and incubated overnight. Single colonies were isolated by plating enrichments onto M8 medium agar. Totally 120 different colonies were isolated from the collected samples. The A. spanius STE 11 strain showed the highest TNT degradation capacity in this study and was identified by applying 16S intergenic spacer (ITS) ribosomal DNA analysis. The procedure described in Sarioglu et al. (2012) was followed for ribosomal DNA analysis. DNeasy Blood \& Tissue Kit (QIAGEN, Germany) was used for DNA isolation. Following this, PCR amplification and sequencing steps were taken by modifying the protocol reported by Rijpens et al. (1998). Firstly, 0.2 mM dNTP, 1.25 U Platinum Taq polymerase, 0.4 pmol T3 (ATTAACCCTCACTAAAGGGA) and T7 (TAATACGACTCACTATAGGG) primers (Nagashima et al., 2003) encompassing the entire $16 \mathrm{~S}$ gene, $1.5 \mathrm{mM} \mathrm{MgCl}$ were completed a total volume of $50 \mu \mathrm{l}$ with $1 \times$ Taq buffer. Next, initial denaturation (96 ${ }^{\circ} \mathrm{C}$ for $5 \mathrm{~min}$ ), denaturation (30 cycles, at $96{ }^{\circ} \mathrm{C}$ for $30 \mathrm{~s}$ ), annealing $\left(55^{\circ} \mathrm{C}\right.$ for $\left.30 \mathrm{~s}\right)$, elongation $\left(72{ }^{\circ} \mathrm{C}\right.$ for $\left.30 \mathrm{~s}\right)$ and final elongation $\left(72{ }^{\circ} \mathrm{C}\right.$ for $5 \mathrm{~min}$ ) steps were followed. For sequencing, 130xl Genetic Analyzer, with the help of BigDye Terminator v3.1 Cycle Sequencing Kit (Applied Biosystems, USA) were used. Lastly, samples were analyzed via ABI 3130xl Genetic Analyzer. The results were compared to those in the National Center for Biotechnology Information (NCBI) BLAST database (http://blast.ncbi.nlm.nih.gov/ Blast.cgi) for species identification.

\subsection{Monitoring of TNT biodegradation and metabolite analysis}

In order to identify TNT catabolism products, $10^{8}$ cells $/ \mathrm{mL}$ were first cultivated in $\mathrm{M} 8$ medium $(0.1 \% \mathrm{v} / \mathrm{v})$ for $20 \mathrm{~h}$ at $30^{\circ} \mathrm{C}$ on a rotary shaker at $125 \mathrm{rpm}$ in aerobic conditions. Aliquots were then taken from the inocula at $1 \mathrm{~h}$ intervals to determine the growth rates and the remaining TNT concentrations. The growth rate of STE 11 strain was obtained by either measuring the optical density at $600 \mathrm{~nm}$ or determining colony-forming units in M8 medium agar. TNT reduction was determined by colorimetric nitrite $\left(\mathrm{NO}_{2}\right)$, nitrate $\left(\mathrm{NO}_{3}\right)$, and ammonia $\left(\mathrm{NH}_{4}\right)$ measurements (Mével and Prieur, 2000) as well as by HPLC (Walsh, 2001; Schmidt et al., 2006; Rahal and Moussa, 2011) and FT-IR measurements (Grube et al., 2008; Naumann, 2011).

Metabolite analysis via HPLC was performed for both M8 and M9 media. HPLC-grade acetonitrile was blended with the culture supernatant of equal volume and swirled for $5 \mathrm{~min}$. Next, the final aliquot was filtered via membrane filters (pore size: $0.2 \mu \mathrm{m}$ ) to eliminate the cells and large-sized particles and the sample was subsequently analyzed by HPLC. Injected sample volume was $5 \mu \mathrm{L}$ for every run. Analytes were separated by using an Inertsil Phenyl-3 analytical column $(150 \mathrm{~mm} \times 4.6 \mathrm{~mm}, 5 \mu \mathrm{m})$ (GL Sciences, USA) at room temperature. The column was eluted under a gradient condition through acetonitrile and double-distilled water at a flow rate of $1.4 \mathrm{~mL} / \mathrm{min}$. In the gradient method, the initial acetonitrile ratio 
was raised from $20 \%$ to $60 \%$ between 0 and $25 \mathrm{~min}$. From 25 min to $28 \mathrm{~min}$, the acetonitrile ratio was decreased to $20 \%$ again. The total runtime was fixed at $28 \mathrm{~min}$. All measurements were performed on a Agilent 1200 Series HPLC system with a detector at $254 \mathrm{~nm}$. TNT and TNT metabolites were analyzed and quantified using HP Chemstation software.

During growth, $\mathrm{NO}_{2}, \mathrm{NO}_{3}$, and $\mathrm{NH}_{4}$ releases were assayed hourly using commercial Spectroquant test kits (Merck, Germany). The bacterial growth was regularly monitored during the degradation course and in every $6 \mathrm{~h}$ aliquots were collected from culture media; then, centrifuged at $5000 \times \mathrm{g}$ for $10 \mathrm{~min}$; after that; the supernatants were used for the determination of $\mathrm{NO}_{2}, \mathrm{NO}_{3}$, and $\mathrm{NH}_{4}$ (Mével and Prieur, 2000). For $\mathrm{NO}_{2}$ analysis, $5 \mathrm{~mL}$ aliquot was pipetted into the test tube, which contains Reagent $\mathrm{NO}_{2}-1$. Then the tube was shaken vigorously until the reagent was dissolved completely. After $10 \mathrm{~min}$, the resulting solution was measured by spectroscopy. For $\mathrm{NO}_{3}$ analysis, 1 microspoon of $\mathrm{NO}_{3}-1 \mathrm{~K}$ powder was added to the $\mathrm{NO}_{3}$ test tube and shaken for $1 \mathrm{~min}$. After that, $1.5 \mathrm{~mL}$ aliquot was placed in the same test tube and shaken briefly. The spectroscopic measurement was done after $10 \mathrm{~min}$. For $\mathrm{NH}_{4}$ analysis, $5 \mathrm{~mL}$ aliquot was added into a test tube with Reagent $\mathrm{NH}_{4}-1 \mathrm{~K}$ and shaken vigorously till the reagent was dissolved. After $15 \mathrm{~min}$, the final solution was measured by spectroscopy. Triplicate sets of experiments were performed for the evaluation of the selected bacterial strain. In addition, elemental analysis measurements were carried out to detect the level of nitrogen introduced into the cell biomass. $30 \mathrm{~mL}$ of cultured M8 media was centrifuged at 14,000 rpm. The remaining pellets were washed twice through distilled water and dried overnight at $45{ }^{\circ} \mathrm{C}$. Control measurements were conducted in non-inoculated media under the same conditions.

FT-IR spectroscopy was used for monitoring changes in the strain in the presence of TNT. Samples were inoculated in both Luria Bertani and M8 media, and $1 \mathrm{~mL}$ aliquots were drawn from each culture. Supernatants were removed after centrifugation at $14,000 \mathrm{rpm}$ for $5 \mathrm{~min}$. Cell pellets were washed twice with physiological saline $(0.9 \% \mathrm{w} / \mathrm{v}$ of $\mathrm{NaCl})$ and stirred with distilled water. $20 \mu \mathrm{L}$ of the final solution was dried at $45^{\circ} \mathrm{C}$ for $1 \mathrm{~h}$ (Gomez et al., 2006; Claus et al., 2007; Naumann, 2011). FT-IR spectra were collected over a wavenumber range between 4000 and $400 \mathrm{~cm}^{-1}$ using a Nicolet 6700 FT-IR Spectrometer (Thermo-Scientific, USA). The ground corrections of $\mathrm{CO}_{2}$ and water were applied automatically before measurements. Control of the system was by OMNICTM software (Sarioglu et al., 2012). The FT-IR of M8 medium was used as reference spectrum in order to determine the differences caused by TNT. Samples were analyzed in triplicate.

\subsection{Optimization of temperature and $\mathrm{pH}$}

The $\mathrm{pH}$ tolerance of the isolate was identified by testing bacterial growth in modified M8 and LB media (inoculation level: $0.1 \%, \mathrm{v} / \mathrm{v}$ ) at $\mathrm{pH}$ values of between 1.0 and 14.0. The $\mathrm{pH}$ of the media was adjusted using $1 \mathrm{~N} \mathrm{HCl}$ and $1 \mathrm{~N} \mathrm{NaOH}$. TNT levels were monitored hourly using HPLC. Both M8 and LB cultures were incubated between 0 and $50{ }^{\circ} \mathrm{C}$ and growth was monitored over $24 \mathrm{~h}$ to examine the temperature reliability of STE 11 strain. All experiments were performed in duplicate and autoclaved cultures served as the control group.

\subsection{Statistical analysis}

Statistical analyses were done by Minitab (Minitab Inc., USA) statistical software package. Student's $t$-test was used for statistical evaluation at $5 \%$ level of significance.

\section{Results}

\subsection{TNT degradation}

Soil samples collected from both TNT-contaminated production facilities and explosion areas, accordingly 120 bacterial colonies were isolated from these regions. The colonies were tested for their TNT degradation capacities via HPLC, which showed that STE 11 strain exhibited a fast and high degradation activity (99.9\% of the initial amount, in $20 \mathrm{~h}$ ) of the 120 strains. Typical growth and TNT degradation curves of $A$. spanius STE 11 strain are shown in Fig. 1. As the biomass of the strain STE 11 increased, the remaining TNT amount decreased during the growth period.

Next, the formation of 2,4-DNT and 2,6-DNT were observed particularly over the first $5 \mathrm{~h}$ Fig. 2 shows that the 2,4-DNT level reached a maximum of $7 \mathrm{mg} \mathrm{L}^{-1}$ after $4 \mathrm{~h}$. The amount of 2,6-DNT in the active culture was at the highest point after $4 \mathrm{~h}$, reaching $3 \mathrm{mg} \mathrm{L}{ }^{-1}$. The 2-ADNT and 4-ADNT concentrations increased exponentially between 4 and $20 \mathrm{~h}$ (Fig. 2). The maximum concentrations of 2-ADNT and 4-ADNT were 16 and $49 \mathrm{mg} \mathrm{L}^{-1}$, respectively. In TNT-containing ( $100 \mathrm{mg} \mathrm{L}^{-1}$ ) M8 medium, A. spanius STE 11 converted TNT to transformation products (ADNTs, DNTs, $\mathrm{NO}_{3}$, and $\mathrm{NH}_{4}$ ), however in TNT-free M8 medium, the strain did not produce abovementioned products. This pattern suggests that the strain is able to use TNT as its sole nitrogen source and to convert TNT to its metabolites.

\subsection{Nitrogen balance during the degradation of TNT}

The amount of TNT incorporated into the cell biomass was determined by measuring the amount of nitrogenous compounds released into the medium by STE 11 . Concentrations of $\mathrm{NO}_{2}, \mathrm{NO}_{3}$, and $\mathrm{NH}_{4}$ were tracked for $48 \mathrm{~h}$ and STE 11 cells were found to have an active nitrogen metabolism when TNT is the sole nitrogen source. The $\mathrm{NO}_{3}$ level increased sharply between 0 and $6 \mathrm{~h}$ and remained stable until $18 \mathrm{~h}$, then slowly decreased to undetectable levels (Fig. 3). The minimum and the maximum $\mathrm{NO}_{2}$ concentrations were $0.02 \mathrm{mg} \mathrm{L}^{-1}$ and $0.07 \mathrm{mg} \mathrm{L}^{-1}$, respectively, whereas $\mathrm{NH}_{4}$ levels rose up to $2.58 \mathrm{mg} \mathrm{L}^{-1}$ during the growth process.

A possible degradation pathway can be described regarding to the formation and disappearance of these metabolites (Fig. 4). Initially, the TNT molecule was transformed to DNTs (Spain et al., 2000; Solyanikova et al., 2012). Meanwhile, the hydrolysis of the amino groups resulted in the transformation of the TNT into ADNTs,

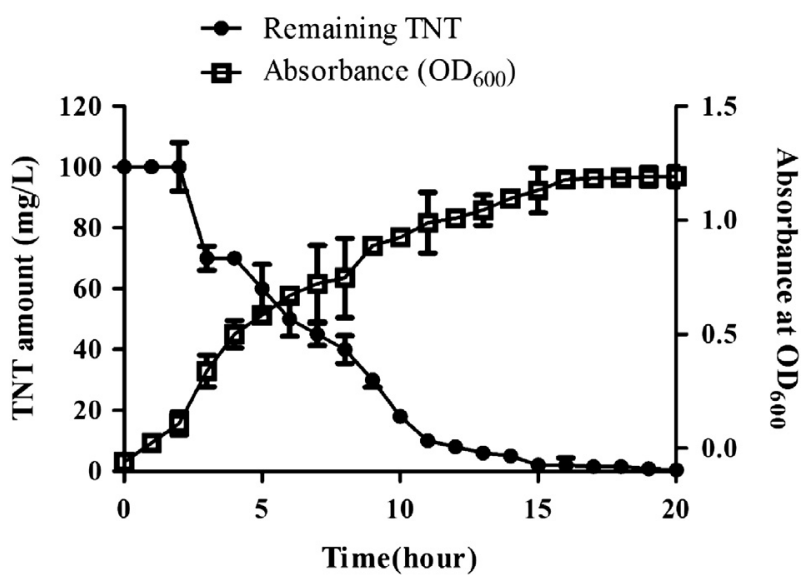

Fig. 1. TNT degradation rate vs. bacterial growth of STE 11 strain. Time course of bacterial growth regarding to the change of turbidity (the absorbance) and TNT degradation in TNT-contained cultures. 


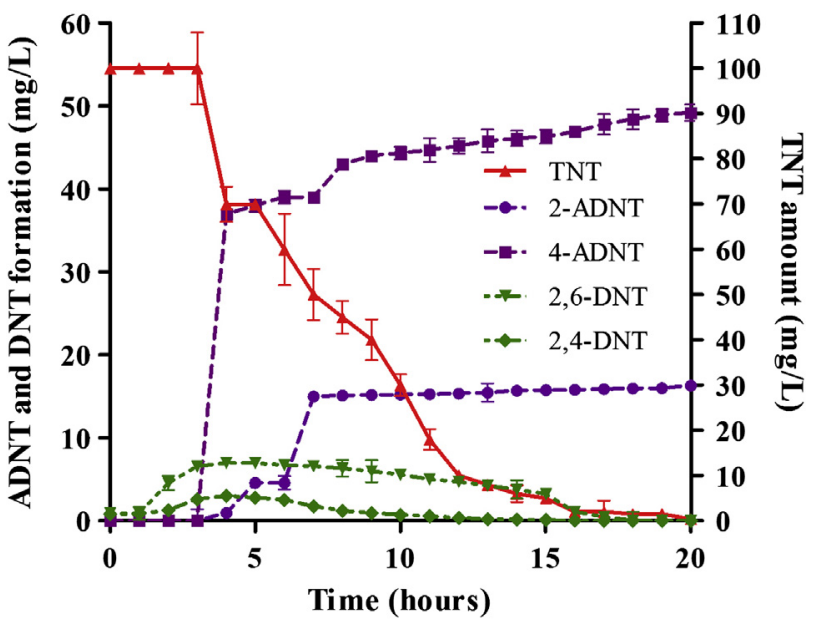

Fig. 2. 2-ADNT and 4-ADNT formation rates of STE 11. The formation of 2,4-DNT and 2,6-DNT were observed over the first $5 \mathrm{~h}$ then, the 2-ADNT and 4-ADNT concentrations increased exponentially between 4 and $20 \mathrm{~h}$.

which were the key degradation products and the most commonly accumulated metabolites. In addition, DNTs were formed transiently and were possibly metabolized by STE 11 cells, as no DNT accumulation was observed at the end of the experiment. Two adjacent peaks of unknown metabolites (Fig. 4) that were reported in the literature (Fiorella and Spain, 1997; Claus et al., 2007; Kubota et al., 2008; Lorme and Craig, 2009; Rylott et al., 2010) were detected between 15 and $20 \mathrm{~h}$.

TNT degradation by STE 11 strain was confirmed using FT-IR spectroscopy. Fig. 5 shows FTIR spectra of STE 11 bacteria at $20 \mathrm{~h}$ both in TNT-free and TNT-containing (100 $\left.\mathrm{mg} \mathrm{L}^{-1}\right)$ culture media. Considerable surface reflection spectra of TNT were detected around $1530 \mathrm{~cm}^{-1}$, as reported previously by Gomez et al. (2006) and Naumann (2011). The IR spectroscopic signatures revealed the TNT-related changes in TNT-free and TNT-containing samples during the growth period. The $1600 \mathrm{~cm}^{-1}$ region was determined to be the marker of strain STE 11 and indicated differences in spectra intensities of $\mathrm{N}_{2}, \mathrm{C}$, and glucose changes. Furthermore, Fig. 5 shows a significant decrease in amide I $\left(1544 \mathrm{~cm}^{-1}\right)$ and amide II $\left(1655 \mathrm{~cm}^{-1}\right)$ peaks for STE 11 strain after $20 \mathrm{~h}$ of incubation. Other changes were observed at $910 \mathrm{~cm}^{-1}, 1087 \mathrm{~cm}^{-1}, 1171 \mathrm{~cm}^{-1}$ and $1350 \mathrm{~cm}^{-1}$ for $2,6-\mathrm{NO}_{2}$ scissors and $\mathrm{C}-\mathrm{H}$ stretching, $\mathrm{C}-\mathrm{H}$ ring

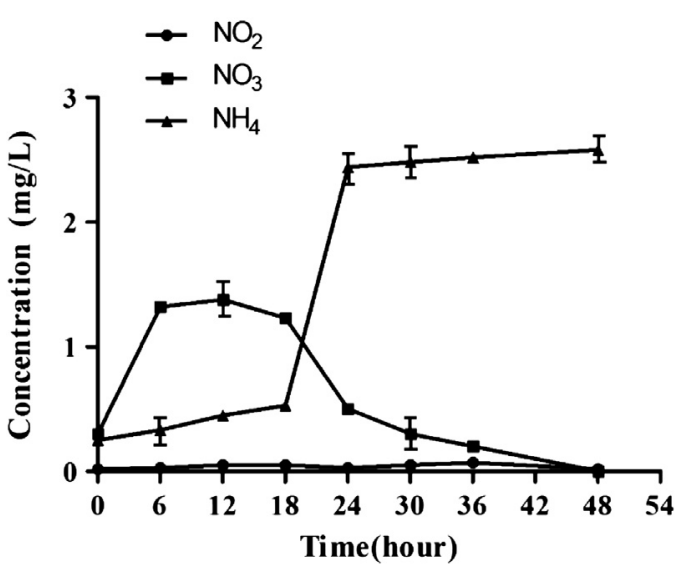

Fig. 3. Changes in $\mathrm{NO}_{2}, \mathrm{NO}_{3}$, and $\mathrm{NH}_{4}$ amounts in the supernatant of culture media. $\mathrm{NO}_{2}$ levels were in minute amounts during the degradation. Immediately after the beginning of TNT degradation process, $\mathrm{NO}_{3}$ and $\mathrm{NH}_{4}$ compounds were observed through the degradation course. vibration, $\mathrm{C}-\mathrm{C}$ implane ring trigonal band, 2,4,6-C-N and $\mathrm{C}-\mathrm{CH}_{3}$ stretching, and $\mathrm{NO}_{2}$ group band symmetric stretching vibration, respectively.

The TNT degradation capacity of strain STE 11 was tested at several temperature and $\mathrm{pH}$ values to determine optimal conditions for remediation. Fig. 6 showed that STE 11 had higher degradation activity at $\mathrm{pH} 6.0-7.0$ and $30{ }^{\circ} \mathrm{C}$ than other at temperature and $\mathrm{pH}$ combinations, in agreement with the previous observations (Spain et al., 2000).

In addition, M9 culture helped to understand how the biodegradation efficiency changes in STE 11 strain in the presence of an additional nitrogen source $\left(\mathrm{NH}_{4} \mathrm{Cl}\right)$. TNT degradation efficiency in M8 medium was higher compared to that for M9 medium, which was confirmed by HPLC results and growth rates. Despite the fact that the bacterial growth was stimulated by the presence of $100 \mathrm{mg} \mathrm{L}^{-1}$ TNT in M9 medium (data not shown), the TNT degradation capacity of $A$. spanius STE 11 was found to be $70 \%$ of the initial amount of TNT (100 $\left.\mathrm{mg} \mathrm{L}^{-1}\right)$ within the first $24 \mathrm{~h}$ in M9 medium.

\subsection{Identification and imaging}

The STE 11 strain has the following physiological and biochemical characteristics: Gram negative $\left(\mathrm{G}^{-}\right)$, rod shape, non-spore forming, and aerobic. The colonies of the strain STE 11 were smooth and yellow after overnight incubation. The 16S ITS ribosomal DNA analyses of STE 11 strain shows $99.8 \%$ similarity with $A$. spanius based on a BLAST search. The sequence obtained for STE 11 strain was submitted to the GenBank database (http://blast.ncbi.nlm.nih.gov/Blast. cgi) under the access number JX312286 (Supplementary data).

\section{Discussion}

In the present study, A. spanius STE 11 was shown for the first time to efficiently degrade TNT as the sole source of nitrogen in $20 \mathrm{~h}$. The strain was isolated from munitions-contaminated regions and showed higher and more effective TNT degradation compared to previous reports (Sitzmann, 1974; Kalafut et al., 1998; Vorbeck et al., 1998; Snellinx et al., 2002; Lewis et al., 2004; Cohen et al., 2007; Smets et al., 2007).

A. spanius STE 11 strain was shown to degrade TNT via denitration and nitro group reduction in aerobic conditions. After $3 \mathrm{~h}$, DNTs accumulated in the culture medium as first step intermediates and subsequently ADNTs were observed. DNT accumulation is desirable because it is previously shown in the literature that DNTs are reduced through dioxygenase attack to yield 4-methyl-5-nitrocatechol, which is sequentially mineralized (Spanggord et al. 1991; Martin et al., 1997). Furthermore, two unknown intermediates were detected as dead-end products of degradation. It is likely that these metabolites were two different conformations of unstable nitroreductase products (Fiorella and Spain, 1997; Claus et al., 2007; Kubota et al., 2008; Lorme and Craig, 2009; Rylott et al., 2010).

In the current study, $A$. spanius STE 11 was grown successfully in the nitrogen-free M8 medium supplemented with TNT (Fig. 1), presumably because of its high TNT tolerance and utilization capacity. The strain could utilize TNT immediately after being introduced into a TNT-containing medium; as previously reported by Kumagai et al. (2000), it is likely that $A$. spanius STE 11 has a constitutive nitroreductase or a similar enzyme activity. Since there is no nitrogen-containing compound other than TNT in the cultured M8 medium, the detection of $\mathrm{NO}_{2}, \mathrm{NO}_{3}$ and $\mathrm{NH}_{4}$ is a direct indicator of TNT catabolism. In general, $\mathrm{NO}_{2}$ levels were in minute amounts because of the aerobic metabolism of the described strain. The complete removal of TNT resulted in the formation of $\mathrm{NH}_{4}$ within 

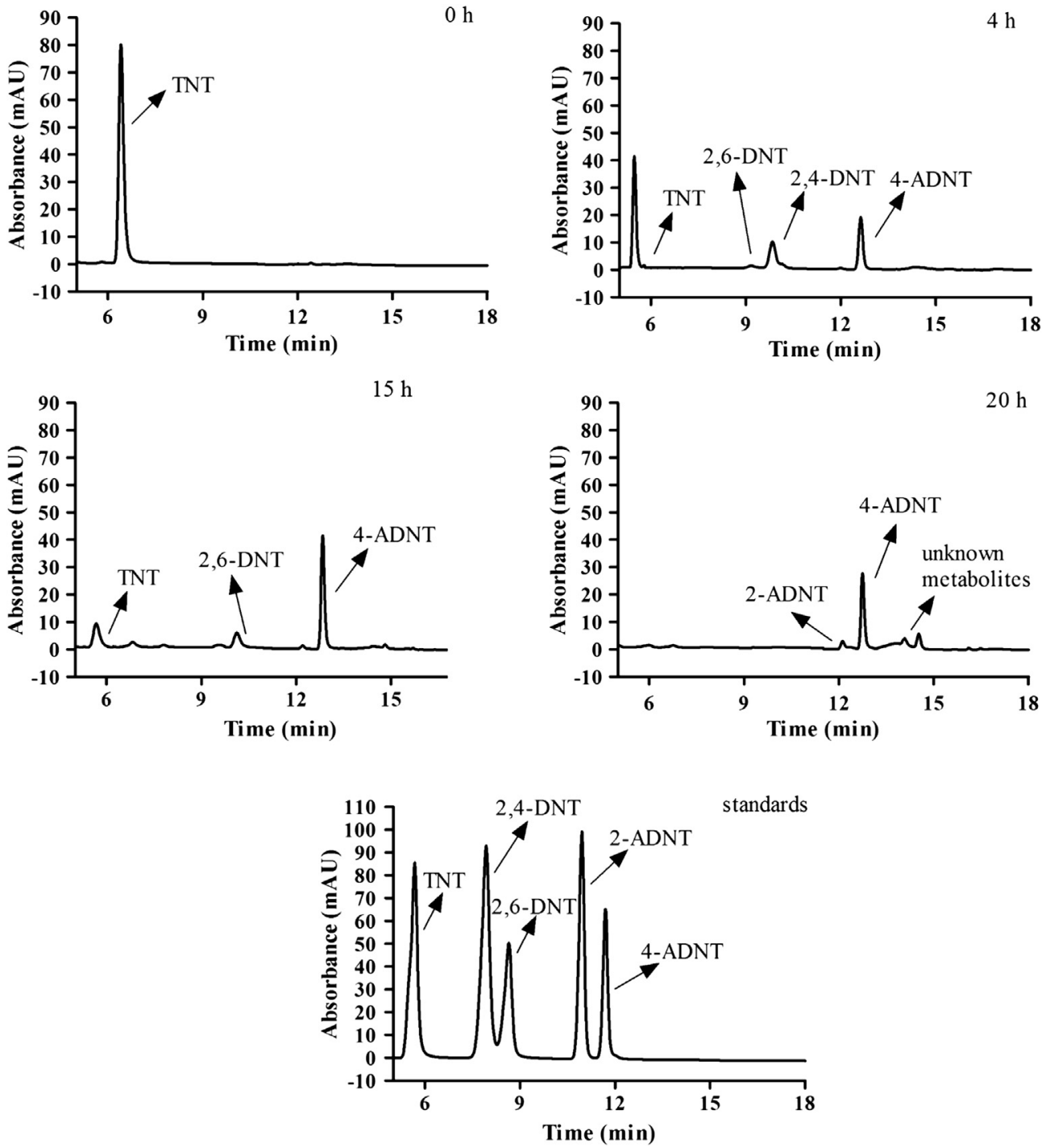

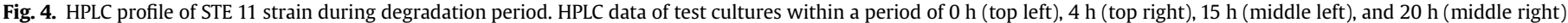
together with standard metabolites (bottom).

$20 \mathrm{~h}$ (Kumagai et al., 2000). $\mathrm{NO}_{3}$ was probably produced at the first stage of TNT transformation, and subsequently converted to other forms, such as $\mathrm{NH}_{4}$. In A. spanius STE 11 culture media, $\mathrm{NO}_{3}$ was observed to be present in the supernatant immediately after TNT degradation started. This pattern suggests that nitroreductases are constitutively expressed in A. spanius STE 11 and TNT is denitrated to DNT isomers, similar to results that were reported by Rahal and Moussa (2011). In addition, the usage of an additional nitrogen
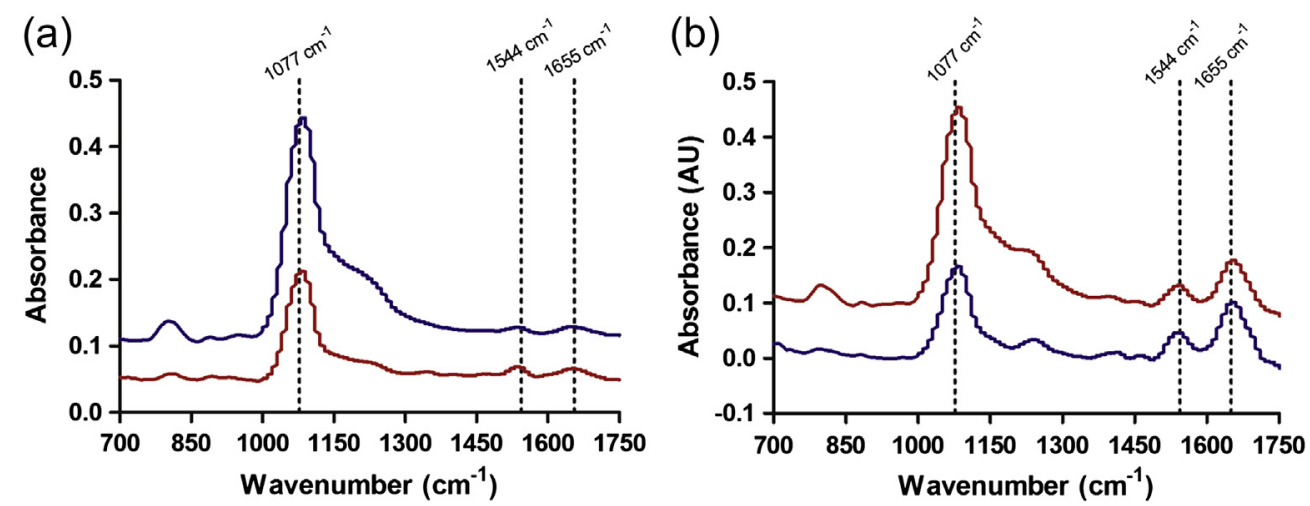

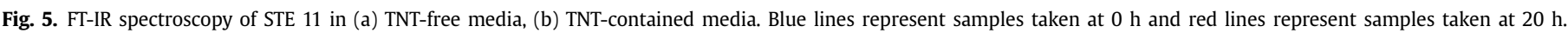
(For interpretation of the references to color in this figure legend, the reader is referred to the web version of this article.) 
(a)

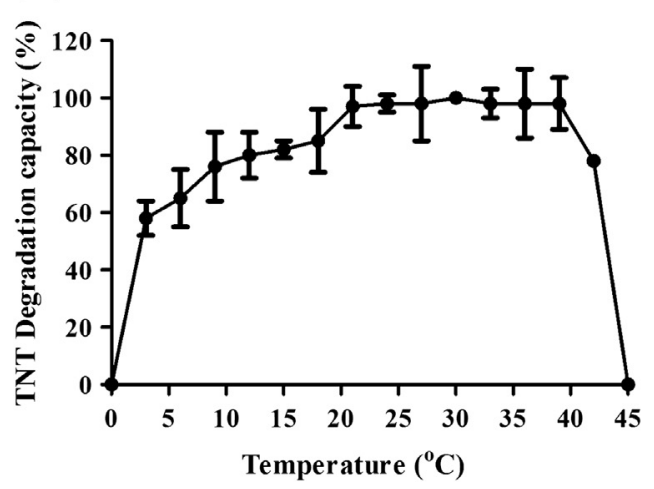

(b)

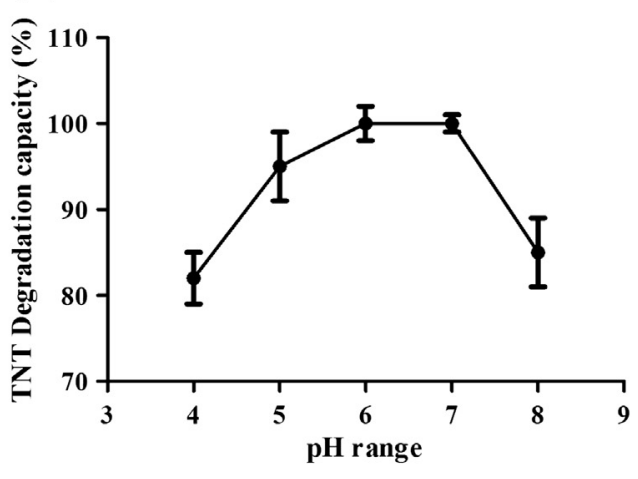

Fig. 6. Impact of temperature and $\mathrm{pH}$ changes on STE 11. (a) temperature changes at pH 7, (b) pH changes at $30{ }^{\circ} \mathrm{C}$. The data are taken from 20 h samples.

source in M9 medium decreased the TNT transformation capacity from $100 \%$ to $42 \%$. It is clear that the STE 11 was capable of using TNT with a relatively decreased degradation capacity even if there is an additional nitrogen source in the growth medium.

The results of HPLC, colorimetric tests, and elemental analysis measurements were in excellent agreement with FT-IR bands observed for STE 11 strain. The intensity of bonds at $1602 \mathrm{~cm}^{-1}$ $\left(\mathrm{NH}_{2}, \mathrm{NH}_{3}, \mathrm{~N}-\mathrm{NO}_{2}\right.$ and $\mathrm{C}=\mathrm{C}$ bonds), $1410 \mathrm{~cm}^{-1}$ (C-N amines) and $1077 \mathrm{~cm}^{-1}\left(\mathrm{C}-\mathrm{O}-\mathrm{C}, \mathrm{C}=\mathrm{O}, \mathrm{P}=\mathrm{O}\right.$, and $\mathrm{PO}_{2}$ attractions $)$ was significantly different because of the dynamics of bacterial growth was affected by TNT presence. Changes in the $1606 \mathrm{~cm}^{-1}$ region were evidence that the strain transformed TNT during growth. In addition, the presence of TNT affected nitrogen metabolism as demonstrated by the intensities of amide I $\left(1544 \mathrm{~cm}^{-1}\right)$ and amide II $\left(1655 \mathrm{~cm}^{-1}\right)$ spectra. The peaks observed in Amide I (1544 cm-1) and amide II $(1655 \mathrm{~cm}-1)$ together with the fingerprint of TNT $(1530 \mathrm{~cm}-1)$ spectra consolidated the conclusion that only TNT was used by the strain STE 11 as a sole nitrogen source during the degradation period. Moreover, the FT-IR data provided an insight of the nitrogen-starvation effect on cells by showing qualitative and discriminative differences in the culture composition of the studied STE 11 strain and the response of the bacteria to TNT during degradation period. FT-IR spectra results were similar to those reported in previous studies (Kumagai et al., 2000; Gomez et al., 2006; Maeda et al., 2006; Grube et al., 2008).

Elemental analyses were conducted to detect the amount of nitrogen that was dissociated from TNT and incorporated into the cell biomass. Nitrogen levels in A. spanius STE 11 cells increased gradually up to $24.77 \mathrm{mg} \mathrm{L}^{-1}$ during the growth period. In 20th h, the highest nitrogen level was reached $\left(24.77 \mathrm{mg} \mathrm{L}^{-1}\right)$, suggesting that the bacteria can effectively utilize TNT as its sole nitrogen source and incorporate TNT into the cell biomass. The high cellular accumulation of nitrogen observed in the elemental analysis might also be caused by reduced nitrogen availability due to the use of TNT as the exclusive nitrogen source. Furthermore, "starvationlike" effects might cause the bacterial cells to accumulate nitrogen in the cell biomass. The relative nitrogen changes during degradation period can be explained as follows (the means and standard deviations were placed together in the form of mean of five different replicates \pm SD.): Although no nitrogen participation was detected in the cell biomass at $0 \mathrm{~h}$, the nitrogen participation increased to be $3.03 \%( \pm 0.64 \%)$ at $6 \mathrm{~h}$. This percentage continued to rise at $12 \mathrm{~h}$ and became $13.2 \%( \pm 2.14 \%)$ and finally reached to $24.77 \%( \pm 1.22 \%)$ at $20 \mathrm{~h}$. According to the statistical analyses, no statistically significant difference was detected between same hour samples for nitrogen amounts $(P>0.05)$. To conclude, the nitrogen balance analysis revealed that $24.77 \%( \pm 1.22 \%)$ of the TNT participated in the cell biomass while 75\% of the TNT was converted to DNTs and ADNTs during the incubation period. The remaining $0.23 \%$ of nitrogen was not detected and might be released as nitrogen gas - as a result of denitration process - or converted to unknown metabolites during the degradation process.

This study showed that $A$. spanius STE 11 strain could transform TNT completely through denitration and nitro group reduction in $20 \mathrm{~h}$. The results showed that TNT could be incorporated into the cell biomass and reduced to DNT and ADNT isomers together with an unknown metabolite through enzymatic reactions. In addition, the strain was able to preserve the high degradation capacity in $\mathrm{pH}$ and temperature ranges that are broader than those of described in the literature (Rieger and Knackmuss, 1995; Spain et al., 2000). The results suggest that the strain STE 11 can be utilized both safely and effectively in TNT biodegradation. Further study to gain more detailed understanding of TNT degrading enzymes from $A$. spanius STE 11 strain will be valuable to elucidate alternative TNT degradation pathways for bacteria.

\section{Acknowledgments}

This work was supported by the Republic of Turkey, Ministry of Science, Industry and Technology under the Project No. STZ-004802009-2. The authors would like to thank Zafer Pesen from the Mechanical and Chemical Industry Corporation and Halil Karatas from the Brass Factory for their cooperation. The authors acknowledge Jalal Hawari, Alper Devrim Ozkan, Talha Erdem, and Mustafa Akin Sefunc for fruitful discussions.

\section{Appendix A. Supplementary data}

Supplementary data associated with this article can be found, in the online version, at http://dx.doi.org/10.1016/j.ibiod.2013.06.007.

\section{References}

Claus, H., Bausinger, T., Lehmler, I., Perret, N., Fels, G., Dehner, U., Preuß, U., König, H. 2007. Transformation of 2,4,6-trinitrotoluene (TNT) by Raoultella terrigena. Biodegradation 18, 27-35.

Cohen, R., Zeiri, Y., Wurzberg, E., Kosloff, R., 2007. Mechanism of thermal unimolecular decomposition of TNT (2,4,6-trinitrotoluene)- A DFT study. Journal of Physical Chemistry A 111, 11074-11083.

Dillert, R., Brandt, M., Fornefett, I., Siebers, U., Bahnemann, D., 1995. Photocatalytic degradation of trinitrotoluene and other nitroaromatic compounds. Chemosphere 30, 2333-2341.

Drzyzga, O., Bruns-Nagel, D., Gorontzy, T., Blotevogel, K.H., Gemsa, D., von Löw, E. 1998. Mass balance studies with ${ }^{14} \mathrm{C}$-labeled 2,4,6-trinitrotoluene (TNT) mediated by an anaerobic Desulfovibrio species and an aerobic Serratia species. Current Microbiology 37, 380-386. 
Environmental Protection Agency, 1989. Health Advisory for TNT, Criteria and Standard Division. Office of Drinking Water, Washington.

Fiorella, P.D., Spain, J.C., 1997. Transformation of 2,4,6-trinitrotoluene by Pseudomonas pseudoalcalligenes JS52. Applied Environmental Microbiology 63, 2007-2015.

Gandia-Herrero, F., Lorenz, A., Larson, T., Graham, I.A., Bowles, D.J., Rylott, E.L. Bruce, N.C., 2008. Detoxification of the explosive 2, 4, 6-trinitrotoluene in Arabidopsis: discovery of bifunctional O- and C-glucosyltransferases. The Plant Journal 56, 963-974.

Gao, D., Du, L., Yang, J., Wu, W.M., Liang, H., 2010. A critical review of the application of white rot fungus to environmental pollution control. Critical Reviews in Biotechnology 30, 70-77.

Gomez, L.M., Osorio, C., Amman, E., Hernandez, S.P., Castro, M.E., 2006. The spectroscopic fingerprint of TNT between 395 and $495 \mathrm{~nm}$ determined from transmission near field optical microscopy measurements. Chemical Physics Letters 422, 313-316.

Grube, M., Muter, O., Strikauska, S., Gavare, M., Limane, B., 2008. Application of FT-IR spectroscopy for control of the medium composition during the biodegradation of nitroaromatic compounds. Journal of Industrial Microbiology and Biotechnology 35, 1545-1549.

Hao, O.J., Phull, K.K., Davis, A.P., Chen, J.M., Maloney, S.W., 1993. Wet air oxidation of trinitrotoluene manufacturing red water. Water Environment Research 65, $213-220$.

Kalafut, T., Wales, M.E., Rastogi, V.K., Naumova, R.P., Zaripova, S.K., Wild, J.R., 1998 Biotransformation patterns of 2,4,6-trinitrotoluene by aerobic bacteria. Current Microbiology 36, 45-54

Kubota, A., Maeda, T., Nagafuchi, N., Kadokami, K., Ogawa, H.I., 2008. TNT biodegradation and production of dihydroxylamino-nitrotoluene by aerobic TNT degrader Pseudomonas sp. strain TM15 in an anoxic environment. Biodegradation 19, 795-805.

Kumagai, Y., Wakayamaa, T., Li, S., Shinoharad, A., Iwamatsud, A., Sunc, G. Shimojoa, N., 2000. C-Crystallin catalyzes the reductive activation of $2,4,6$ trinitrotoluene to generate reactive oxygen species: a proposed mechanism for the induction of cataracts. FEBS Letters 478, 295-298.

Letzel, S., Göen, T., Bader, M., Angerer, J., Kraus, T, 2003. Exposure to nitroaromatic explosives and health effects during disposal of military waste. Occupational Environmental Medicine 60, 483-488.

Lewis, T.A., Newcombie, D.A., Crawford, R.L., 2004. Bioremediation of soils contaminated with explosives. Journal of Environmental Management 70, 291-307.

Lorme, M.D., Craig, M., 2009. Biotransformation of 2,4,6-trinitrotoluene by pure culture ruminal bacteria. Current Microbiology 58, 81-86.

Macek, T. Novakova, M., Kotrba, P., Viktorova, J., Lovecká, P., Fiser, J., Vrbova, M Tejklova, E., Najmanova, J., Domnerova, K., Mackova, M. (Eds.), 2012. Genetically modified plants designed for phytoremediation of toxic organic and inorganic contaminants. In: Naser, A., Anjum, M.E., Pereira I.A., Armando C.D., Shahid, U. (Eds.), Phytotechnologies: Remediation of environmental contaminants, 415

Maeda, T., Nagafuchi, N., Kubota, A., Kadokami, K., Ogawa, H.I., 2006. One-step isolation and identification of hydroxylamino-dinitrotoluenes, unstable products from 2,4,6-trinitrotoluene metabolites, with thin-layer chromatography and laser time-of-flight mass spectrometry. Journal of Chromatographic Science 44, 96-100.

Martin, J.L., Comfort, S.D., Shea, P.J., Kokjohn, T.A., Drijber, R.A., 1997. Denitration of 2,4,6,-trinitrotoluene by Pseudomonas savastanoi. Canadian Journal of Microbiology 43, 447-455
Mével, G., Prieur, D., 2000. Heterotrophic nitrification by a thermophilic Bacillus species as influenced by different culture conditions. Canadian Journal of Microbiology 46, 465-473.

Nagashima, K., Hisada, T., Sato, M., Mochizuki, J., 2003. Application of new primerenzyme combinations to terminal restriction fragment length polymorphism profiling of bacterial populations in human feces. Applied and Environmental Microbiology 69, 1251-1262.

Naumann, D., 2011. FT-infrared and Ft-raman spectroscopy in biomedical research. Applied Spectroscopy Reviews 36, 239-298.

Rahal, A.G., Moussa, L.A., 2011. Degradation of 2,4,6-trinitrotoluene (TNT) by soil bacteria isolated from TNT contaminated soil. Austrian Journal of Basic Applied Science 5, 8-17.

Rieger, P.G., Knackmuss, H.J., 1995. Basic knowledge and perspectives on biodegradation of 2,4,6-trinitrotoluene and related nitroaromatic compounds in contaminated soil. In: Spain, J.C. (Ed.), Biodegradation of Nitroaromatic Compounds. Plenum Press, New York.

Rijpens, N., Vlaemynck, G., Rossau, R., Herman, L., Jannes, G., 1998. Unidentified listeria-like bacteria isolated from cheese. Letters in Applied Microbiology 27, 198-202.

Rylott, E.L., Bruce, N.C., 2009. Plants disarm soil: engineering plants for the phytoremediation of explosives. Trends in Biotechnology 27, 73-81.

Rylott, E.L., Neil, A., Bruce, N.C., 2010. Biodegradation and biotransformation of explosives. Current Opinion in Biotechnology 22, 1-7.

Sambrook, J., Russell, D.W., 2001. Molecular Cloning: a Laboratory Manual. Cold Spring Harbor Laboratory Press, New York.

Sarioglu, O.F., Suluyayla, R., Tekinay, T., 2012. Heterotrophic ammonium removal by a novel hatchery isolate Acinetobacter calcoaceticus STB1. International Biodeterioration and Biodegradation 71, 67-71.

Schmidt, A.C., Niehus, B., Matysik, F.M., Engewald, W., 2006. Identification and quantification of polar nitroaromatic compounds in explosive-contaminated waters by means of HPLC-ESI-MS-MS and HPLC-UV. Chromatographia 63, 1-11.

Sitzmann, M.E., 1974. Chemical reduction of 2,4,6-trinitrotoluene. Initial products. Journal of Chemical Engineering Data 19, 179-181.

Smets, B.F. Yin, H., Esteve-Nunez, A., 2007. TNT biotransformation: when chemistry confronts mineralization. Applied Microbiology and Biotechnology 76, 267-277.

Snellinx, Z., Nepovim, A., Taghavi, T., Vangronsveld, J., Vanek, T., Van der Leliel, D. 2002. Biological remediation of explosives and related nitroaromatic compounds. Environmental Science and Pollution Research 9, 48-61.

Solyanikova, I.P., Baskunov, B.P., Baboshin, M.A., Saralov, A.I., Golovleva, L.A., 2012. Detoxification of high concentrations of trinitrotoluene by bacteria. Applied Biochemistry and Microbiology 48, 21-27.

Spain, J.C., Hughes, J.B., Knackmuss, H.J. (Eds.), 2000. Biodegradation of Nitroaromatic Compounds and Explosives. Lewis Publishing, Florida.

Spanggord, R.J., Spain, J.C., Nishino, S.F., Mortelmans, K.E., 1991. Biodegradation of 2,4-dinitrotolueneby a Pseudomonas sp. Applied Environmental Microbiology 57, 3200-3205.

Vorbeck, C., Lenke, H., Fischer, P., Spain, J.C., Knackmuss, H.J., 1998. Initial reductive reactions in aerobic microbial metabolism of 2,4,6-trinitrotoluene. Applied and Environmental Microbiology 64, 246-252.

Walsh, M.E. 2001. Determination of nitroaromatic, nitramine, and nitrate ester explosives in soil by gas chromatography and an electron capture detector. Talanta 54, 427-438. 